\title{
Análise de sequências didáticas com abordagem de Ensino por Investigação produzidas por estudantes de licenciatura em Física ${ }^{+*}$
}

\author{
Clara Elena Souza Tabosa ${ }^{1}$ \\ Mestranda em Educação em Ciências e Matemáticas \\ Universidade Federal do Pará \\ Silvana Perez ${ }^{1}$ \\ Universidade Federal do Pará \\ Belém - PA
}

\section{Resumo}

Em uma sociedade cada vez mais globalizada, faz-se necessário repensar um ensino de Ciências que forme cidadãos críticos capazes de se apropriar do conhecimento científico para bem viver na sociedade e com o ambiente. Abordagens didáticas centradas no aluno como o ensino por investigação podem favorecer a aprendizagem e torná-lo protagonista na construção de seu próprio conhecimento. No entanto, formar professores capacitados para trabalhar o desenvolvimento da competência científica em sala não é uma tarefa fácil e exige tanto uma formação inicial específica quanto uma formação epistemológica e teórico-metodológica contínua. Neste trabalho, partimos do pressuposto de que a utilização de abordagens investigativas em disciplinas de conteúdo específico de Física pode estimular e capacitar os professores em formação inicial a incorporar esta abordagem à sua prática docente. Assim, buscou-se analisar qualitativamente as sequências didáticas baseadas em investigação que foram produzidas ao final de um semestre por uma turma de estudantes do curso de licenciatura em Física da Universidade Federal do Pará. Essa turma vivenciou na prática uma disciplina realizada inteiramente no formato da abordagem investigativa. Para a análise, utilizamos uma rubrica que propõe a categorização de sequências didáticas quanto ao grau de presença da

\footnotetext{
${ }^{+}$An analysis of some inquiry-based didactic sequences produced by preservice physics teachers

${ }^{*}$ Recebido: 25 de maio de 2020.

Aceito: 30 de junho de 2021.

11E-mails: clara.taboza@gmail.com; silperez_1972@hotmail.com
} 
abordagem investigativa. Os resultados apontam dificuldades de utilizar abordagens centradas no aluno, de compreender os aspectos teóricos básicos do ensino por investigação e, sobretudo, a dificuldade de romper com o paradigma tradicional de ensino.

Palavras-chave: Formação Inicial de Professores; Sequências Didáticas; Abordagem Investigativa.

\begin{abstract}
In an increasingly globalized society, it is necessary to rethink science teaching in order to form critical citizens capable of appropriating scientific knowledge to live well in society and with the environment. Didactic approaches centered on the student, such as Inquiry, can favor the learning of physical concepts while making them a protagonist in the construction of their own knowledge. However, training teachers capable of working the development of scientific competence in the classroom is not an easy task and requires both specific initial training and epistemological and theoretical-methodological continuous training. In this work, we assume that the use of Inquiry approaches in disciplines with specific content in Physics can stimulate and enable preservice teachers to incorporate this approach into their teaching practice. Thus, we sought to qualitatively analyze inquiry-based teaching sequences that were produced at the end of a semester by a group of students from the undergraduate Physics course at the Federal University of Pará. This class experienced in practice a discipline entirely inquiry-based. For the analysis, we used a taxonomy of didactic sequences regarding the degree of presence of the Inquiry approach. The results point to difficulties in using student-centered approaches, in understanding the basic theoretical aspects of inquiry-based teaching and, above all, the difficulty in breaking with the traditional teaching paradigm.
\end{abstract}

Keywords: Initial Teacher Training; Didactic Sequences; Inquiry Approach.

\title{
I. Introdução
}

Em uma sociedade cada vez mais globalizada e com grande quantidade de meios de comunicação e circulação de informações, faz-se cada vez mais necessário pensar uma 
educação que tenha como objetivo formar cidadãos críticos, capazes de refletir e tomar decisões racionais sobre aquilo que acontece no espaço coletivo.

No cenário do ensino de Ciências, tal educação deve também contribuir para que, ao final de sua educação formal, os cidadãos consigam apropriar-se do conhecimento científico disponível e utilizá-lo para viver melhor em sociedade, sugerindo e realizando transformações condizentes com as necessidades socioambientais do século XXI (MONTEIRO; SILVA; ROSSLER, 2016).

Entretanto, o ensino de Ciências, especificamente no Brasil, ainda enfrenta diversos desafios, mantendo-se distante das metas tanto nacionais quanto internacionais (CACHAPUZ et al., 2005). De um lado, nos anos iniciais, a alfabetização científica é, na maioria das vezes, inexistente (LORENZETTI; DELIZOICOV, 2001) e de outro, no ensino médio, o ensino de ciências é visto de forma descontextualizada, em geral baseado em treinamentos para exames nacionais e vestibulares (MOREIRA, 2018). Como consequência, especificamente em relação à disciplina de Física, há expressiva rejeição por parte dos estudantes, somada a um baixo desempenho.

$\mathrm{Na}$ contramão desta realidade, pesquisas na área de ensino e aprendizagem de Ciências têm fornecido uma literatura rica em resultados que contribuem não apenas para o entendimento do que é necessário fazer para mitigar as problemáticas, como também sobre os possíveis caminhos de como fazê-lo (CARVALHO; GIL-PÉREZ, 2011). Em particular, a utilização de abordagens didáticas ativas de ensino vem se constituindo como uma poderosa ferramenta no ensino de Física, e há uma vasta literatura que corrobora que tais abordagens podem ajudar a proporcionar um processo de ensino-aprendizagem de qualidade, mais próximo das necessidades da sociedade moderna (PARANHOS et al., 2017).

Neste contexto, o ensino de Física por investigação tem apresentado resultados promissores (ZÔMPERO; GONÇALVES; LABURÚ, 2017). Nos Estados Unidos, por exemplo, o ensino de Ciências baseado em investigação já se configura como uma realidade, sustentado por documentos de base instrucional como os produzidos pelo National Research Council e por projetos nacionais como o Science For All Americans que teve início em meados da década de 1980 (NRC, 1996; 2000; 2012; NGSS, 2013).

Também no Brasil há um direcionamento similar em relação ao uso de abordagem investigativa no ensino, presente em documentos oficiais como os Parâmetros Curriculares Nacionais, o Plano Nacional de Educação e a Base Nacional Comum Curricular (BRASIL, 1997; 2014; 2018).

Repensar o ensino de Ciências dentro dos espaços formais de educação deve implicar a reestruturação da prática pedagógica dos professores dentro e fora de sala de aula, a fim de romper, ao menos parcialmente, o paradigma tradicional de seu ensino (CACHAPUZ et al., 2005; GOLOMBEK, 2009). Na maioria das vezes, a prática docente é incoerente com as finalidades do ensino de Ciências, o que faz do mesmo um processo de ensino-aprendizagem mecânico, baseado em uma postura passiva por parte dos estudantes (MOREIRA, 2018). 
Como resultado, tais estudantes acabam não atuando como protagonistas na construção de seu conhecimento, em geral não conseguindo se apropriar criticamente dele, tornando-se assim meros repositórios de informações desconexas de sua realidade cotidiana.

Formar professores capacitados para trabalhar o desenvolvimento das várias dimensões da competência científica (PISA, 2006; CAÑAL, 2012; PEREZ; VILLAGRÁ, 2020) não é uma tarefa fácil e demanda tanto em uma formação específica, para que haja um domínio dos conteúdos que se ensina - posto que é imprescindível que para ensinar Ciências é necessário saber Ciências (CARVALHO; SASSERON, 2018) - quanto uma formação epistemológica e didático-metodológica para o ensino de Ciências (BAPTISTA, 2003; CACHAPUZ et al., 2005). Várias pesquisas sobre uso de atividades investigativas e formação de professores têm sido realizadas, em particular nos últimos anos, e apontam as principais dificuldades nesse processo de mudança da prática pedagógica. Como exemplo, podemos citar as dificuldades em se apropriar de novas abordagens didáticas, construir uma visão epistemológica acerca da natureza da ciência, desenvolver habilidades procedimentais associadas à prática científica, bem como definir critérios objetivos para avaliação. (CAMPOS; SCARPA, 2018; DUARTE, 2018 LIMA; BELÍSSIMO; NARDI, 2020).

No contexto da formação inicial de professores, este trabalho buscou entender de que forma a abordagem de ensino por investigação em disciplinas de conteúdo específico de Física pode influenciar a futura prática docente dos professores em formação inicial. Para isso, buscou-se analisar se eles compreenderam os aspectos básicos da abordagem e se sentiram-se mais estimulados a incorporar esta abordagem à sua prática docente.

Baseando-se nesta questão norteadora, utilizou-se a abordagem investigativa em uma disciplina de primeiro semestre do curso de Licenciatura em Física da Universidade Federal do Pará, denominada Física Elementar Conceitual (TABOSA et al., 2018; PEREZ et al., 2018). No decorrer da disciplina, que apresenta uma revisão da Física vista no ensino médio, os conteúdos foram trabalhados a partir de atividades investigativas.

Ao final do semestre, solicitou-se aos estudantes que construíssem, em equipe, uma sequência didática (SD) com abordagem de ensino por investigação. Estas sequências didáticas produzidas pelos professores em formação inicial constituíram o material de análise desta pesquisa. No delineamento metodológico, utilizou-se o instrumento de análise proposto por Schwarz e Gwekwerere (2007), onde as autoras definem uma rubrica para classificar sequências didáticas de acordo com o grau de presença, maior ou menor, de abordagem investigativa. A partir da análise, são apresentados os resultados acerca da compreensão dos estudantes sobre a abordagem didática e sua potencial capacidade de propor aulas de caráter investigativo após cursar uma disciplina neste formato. 


\section{Fundamentação teórica}

\section{II.1 O Ensino por Investigação}

O ensino por investigação tem por característica principal o envolvimento ativo dos estudantes nos processos de ensino-aprendizagem, para que passem a ser os atores protagonistas na construção de seu próprio conhecimento, por meio do engajamento em atividades de caráter investigativo, em que tenham que resolver ou propor possíveis soluções para situações-problemas; e que durante o processo, lhes seja proporcionado aprender sobre Ciência, sobre o fazer científico e sobre a natureza da Ciência (ZÔMPERO; GONÇALVES; LABURÚ, 2017).

Proposta ainda no Século XIX, no contexto das ideias do filósofo John Dewey para a educação científica (ZÔMPERO; LABURÚ, 2011), a abordagem investigativa, a partir de então, veio ganhando cada vez mais força nos espaços de educação formal de países europeus e dos Estados Unidos durante o século XX, e atualmente ocupa um grande espaço no cenário da América do Sul, ganhando notoriedade de forma crescente no Brasil. Existem diversas metodologias e aportes teóricos em torno desta abordagem, podendo ser considerados pertinentes conforme os objetivos propostos para a sua utilização (MUNFORD; LIMA, 2007).

O ensino por investigação se justifica e se firma como uma proposta para oportunizar situações em que os estudantes aprendam Ciência de uma forma em que se aproximem das práticas científicas, entendendo que a Ciência também é uma construção humana, portanto, dinâmica em todas as suas áreas, e que possui seus métodos próprios de investigação, que definem o fazer científico (BAZZO et al., 2003).

Em suma, o caráter diferencial desta abordagem está em oferecer aos estudantes situações em que possam complexificar sua visão acerca da Ciência, deixando de entendê-la como sendo apenas um conjunto de conceitos isolados, muitas vezes relacionados de forma arbitrária com fórmulas concluídas a serem apenas decoradas e utilizadas para responder questões; ao contrário disto, busca-se com o uso do ensino por investigação que eles aprendam, reflitam e discutam os conceitos, as grandezas, os parâmetros etc. e suas interrelações de maneira crítica e contextualizada.

A abordagem utilizada neste trabalho é a apresentada por Zômpero e Laburú (2016), em que o ensino se dá por meio da realização de atividades de caráter investigativo. As atividades de investigação sempre partem de um problema a ser analisado, para a qual os estudantes devem definir uma pergunta de investigação, elaborar um planejamento de atividades, realizar experimentos, coletar e interpretar dados e emitir conclusões a partir disto (LEDERMAN et al., 2019).

A utilização de sequências didáticas é uma prática comum nas áreas de ensino, em particular no ensino de Física. Na literatura da área é possível encontrar várias definições complementares para este conceito. Neste trabalho, adotou-se a de Zabala (1998) que define sequência didática como sendo um conjunto de atividades que seguem uma ordem lógica e 
que são estruturadas e articuladas a fim de alcançar certos objetivos educacionais. Sequências didáticas baseadas em investigação devem ser construídas com base no ensino por investigação, conforme apresentado na seção anterior.

\section{II.2 Ensino por investigação e formação de professores de Física}

Potencializar a utilização de abordagens ativas na educação básica, necessariamente passa pela reestruturação dos cursos de licenciaturas, o que por si só é um desafio, uma vez que a educação superior brasileira é predominantemente regida pelo paradigma tradicional, manifestado por um ensino fragmentado e descontextualizado da vida de seus estudantes. Segundo Adada (2017), as lacunas na formação docente inicial para o uso destas abordagens pode ser uma dificuldade para a implementação de uma nova prática pedagógica, na qual as abordagens ativas tenham um papel fundamental. É necessário, assim, preparar o professor de forma coerente, oportunizando-lhe situações formativas que os tornem capazes e seguros para se apropriar e utilizar toda e qualquer abordagem e ferramenta que contribua para a construção de um ensino e aprendizagem de qualidade.

Várias pesquisas têm se debruçado sobre esta problemática, analisando os desafios e dificuldades do uso de abordagens ativas no ensino superior, em particular nos cursos de licenciatura, locus do primeiro ciclo formativo do professor. Darub e Silva (2020) identificam dois aspectos principais associados com a dificuldade de utilizar tais abordagens. O primeiro deles, de origem nos alunos, está relacionado com motivação, falta de concentração, lacunas de aprendizagem de conceitos prévios, entre outros. O segundo está associado à falta de recursos didáticos e tecnológicos para a implementação de propostas inovadoras, bem como a pouca formação continuada sobre a temática, justificando assim a ausência de tais propostas na prática docente, tanto no ensino superior quanto na educação básica.

Domingues, Nascimento e Valerio (2019) ressaltam a importância da vivência, durante a formação inicial de professores, nos estágios de imersão em sala de aula da educação básica; e da reflexão sobre a própria prática nestes momentos, quanto ao uso de abordagens alternativas, como o ensino por investigação. Segundo Carvalho, Magno e Perez (2020), os estudantes, em geral, apresentam uma resistência a novas abordagens didáticas, em particular aquelas nas quais deixam de ter uma postura passiva na construção de seu próprio conhecimento. Problemas como organização e divisão das tarefas pelos membros da equipe podem contribuir negativamente para o andamento das atividades (DUARTE, 2018). Falta de comprometimento com o trabalho nas atividades de investigação pode se manifestar em parte dos estudantes. É possível considerar que isso seja um reflexo de experiências pessoais anteriores, uma vez que experiências positivas podem servir como indicadores de capacidade, enquanto que experiências negativas, de incapacidade. Assim, os estudantes acabam antecipando suas ações com base nestas experiências passadas, o que pode prejudicar o seu engajamento e aprendizagem (CARVALHO; CARVALHO; PEREZ, 2020). 
No contexto específico do ensino por investigação, embora os licenciandos reconheçam os benefícios e potencialidades do uso de atividades investigativas, eles ainda veem como um desafio o domínio do conhecimento teórico-metodológico para tal prática (CAMPOS; SCARPA, 2018). Essa visão em parte se justifica pelas concepções e experiências limitantes quanto ao uso de ensino por investigação, haja vista que, estes professores em formação inicial conviveram com a forma tradicional de ensino praticamente a vida inteira (LOTTER; RUSHTON; SINGER, 2016).

As concepções que os professores em formação inicial apresentam sobre ensino, Ciência e sobre os estudantes também podem ser limitantes em relação ao uso de abordagens investigativas (CARDOSO; SCARPA, 2018). Aspectos como a falta de domínio de habilidades associadas com a prática científica, como formular questões de investigação e hipóteses, planejar experimentos, entre outras, também geram dificuldades por parte dos professores na hora de utilizar atividades investigativas (VAN UUM; VERHOEFF; PEETERS, 2016). Conforme afirmam Lima, Belíssimo e Nardi (2020), apesar de os professores em formação sugerirem um planejamento de aula com abordagem investigativa, sua ações pedagógicas são caracterizadas por um paradigma tradicional, centrado na figura do professor, sem proporcionar grau de liberdade intelectual para seus alunos dentro da perspectiva do ensino por investigação.

Segundo Cardoso e Scarpa (2018), os elementos mais presentes nas aulas destes licenciandos são os relacionados com trabalhos empíricos/indutivos, mais especificamente coleta, manejo e registro de dados, elaboração e comunicação de conclusões e trabalho em grupo, havendo pouca utilização de elementos que conferem maior autonomia aos estudantes no processo investigativo, como a reflexão sobre as etapas da prática científica. Resultados similares foram encontrados por Krämer, Nessler e Schlüter (2015). Seung, Park e Jung (2014) também associam parte desta dificuldade à tendência que os docentes em formação inicial apresentam em centrar a atenção e preocupação em si e nas suas ações, em vez de focar no que os estudantes de fato experienciam e aprendem em aulas investigativas. Já Coelho e Ambrózio (2019) pontuam que, ao serem desafiados a planejar e aplicar atividades investigativas na educação básica, discentes de um curso de licenciatura foram capazes de refletir sobre suas práticas pedagógicas, compreendendo os principais aspectos da prática científica.

Outro aspecto a ser considerado no uso de atividades investigativas, tanto no ensino superior quanto na educação básica é a escolha do problema e a dificuldade envolvida na sua solução, uma vez que eles influenciam diretamente no desenvolvimento da argumentação científica do estudante. Um problema bem posto desafia os estudantes, promovendo um maior engajamento da equipe na sua solução, inclusive no que concerne a busca de explicações mais elaboradas embasadas em modelos matemáticos sofisticados (CARVALHO; CARVALHO; PEREZ, 2020). O apoio logístico de uma equipe de técnicos de laboratório também facilita o desenvolvimento das atividades. Enquanto na Educação Básica isso pode ser uma dificuldade, 
no ensino superior esta dificuldade pode ser parcialmente contornada, pois todas as licenciaturas em Física tem obrigatoriamente laboratórios de Física equipados.

Finalmente, o processo de avaliação dos estudantes também é visto como uma dificuldade, em particular no cenário das ciências naturais, onde tanto discentes quanto docentes (em geral com formação em Física e desenvolvendo pesquisas em laboratórios de Física) estão acostumados com provas quantitativas (TABOSA et al., 2018).

Dadas as dificuldades apresentadas tanto pelos professores em formação quanto pelos professores formadores no que diz respeito ao uso de atividades investigativas em sua prática pedagógica, na pesquisa aqui apresentada, buscou-se analisar se o uso de abordagem investigativa em uma disciplina de conteúdo específico de Física no curso de licenciatura facilita o planejamento de atividades de aprendizagem com abordagem investigativa pelos licenciandos.

\section{Metodologia}

A disciplina Física Elementar Conceitual é uma disciplina de primeiro semestre do curso de licenciatura em Física da Universidade Federal do Pará. Sua ementa consiste em uma revisão conceitual da Física que, teoricamente, o estudante deveria ter aprendido na educação básica.

Desde 2017, um projeto-piloto em sendo desenvolvido junto à faculdade, no qual a abordagem didática adotada nesta e em algumas outras disciplinas se baseia em uma perspectiva de ensino por investigação (PEREZ et al, 2018; MUNFORD; LIMA, 2007). No decorrer do semestre, os estudantes trabalham, em equipe, um problema aberto, em geral retirado das listas anuais de problemas propostos no International Young Physicist Tournment (IYPT, 2020), popularmente conhecido como "Copa do Mundo de Física".

Ao final da disciplina, como parte do processo avaliativo, os estudantes têm que escrever, em grupo, um esboço de artigo, explicitando o aporte teórico em que se apoiaram para a compreensão científica do problema, a(s) hipótese(s) a que chegaram, a descrição do aparato experimental (uma vez que a realização do experimento é necessária para obter os dados e testar as hipóteses levantadas), a análise e conclusão acerca dos dados obtidos.

Resultados preliminares da utilização de abordagem investigativa no ano de 2017 , no que se refere ao desenvolvimento de habilidades e competências baseado em atividades de caráter investigativo pode ser encontrado nos trabalhos de Tabosa et al. (2018) e Perez et al. (2018).

Em se tratando do projeto-piloto que vem sendo desenvolvido junto à faculdade, dependendo da disciplina e do interesse do professor, algumas modificações podem ser propostas ao plano de curso original. Assim, no ano de 2018, como parte do processo de avaliação, além da escrita de um artigo, os grupos também tiveram que planejar uma sequência didática baseada em ensino investigativo, usando o mesmo tema do problema 
investigado pelo grupo durante o decorrer da disciplina ou tema semelhante, também como parte de seu processo avaliativo.

O planejamento do curso também foi modificado, e parte da carga horária foi utilizada com o estudo de conteúdos de Física escolhidos pelo docente, e com abordagem de ensino por investigação. Além disso, uma discussão explícita sobre aspectos metodológicos da construção e utilização desta abordagem foi trabalhada por meio de indicação de leitura de artigos e seminários. Desta forma, os discentes vivenciaram a abordagem em dois momentos ao longo do curso. Ao desenvolver a pesquisa do tema do IYPT, como no projeto original, e no estudo de conteúdos específicos propostos pelo professor, e com o uso de sequências de ensino investigativo. Os dois modelos de atividades serviram de base para as equipes construírem as próprias sequências didáticas.

Neste trabalho, apresentamos uma análise qualitativa das sequências didáticas produzidas pelos estudantes quanto ao seu caráter investigativo. Para isso, consideramos uma turma composta por 40 alunos de primeiro semestre do período noturno no ano de 2018. Este estudo objetivou identificar o grau de presença, maior ou menor, do caráter investigativo que os estudantes propuseram no planejamento de suas sequências didáticas.

A metodologia de análise foi baseada em uma rubrica proposta por Schwarz e Gwekwerere (2007), em que podemos encontrar uma categorização composta por seis classes de sequências didáticas, definidas de acordo com seu caráter investigativo e intervenção do professor. Com base nos dados coletados, buscou-se refletir acerca das possíveis dificuldades encontradas por estes estudantes, dentro do seu processo formativo, tanto na compreensão da abordagem didática quanto no planejamento de sequências didáticas baseadas em investigação.

Na Tabela 1 temos a descrição das categorias apresentadas na rubrica de Schwarz e Gwekwerere (2007).

Este instrumento metodológico de análise foi utilizado em vários estudos presentes na literatura, a grande maioria deles relacionada com formação de professores de ciências ensino fundamental, e em língua estrangeira (TOMA; GRECA; VILLAGRÁ, 2017 e referências ali contidas). O presente trabalho traz a utilização desta categorização no contexto brasileiro e na formação de professores de Física para o ensino médio. 
Tabela 1 - Categorização de sequências didáticas proposta por Schwarz e Gwekwerere (2007).

\begin{tabular}{|c|c|}
\hline CATEGORIA & DESCRIÇÃO \\
\hline Prática Incoerente & $\begin{array}{l}\text { Tem como característica principal a } \\
\text { desconexão entre os conceitos abordados e a } \\
\text { situação-problema a ser estudada, com } \\
\text { demasiada ênfase em atividades } \\
\text { experimentais carentes de discussão sobre } \\
\text { sua fundamentação teórica. }\end{array}$ \\
\hline Prática Coerente & $\begin{array}{l}\text { Propõe uma situação-problema que se } \\
\text { resolve de forma totalmente prática } \\
\text { concentrando-se demasiadamente no aparato } \\
\text { experimental, e, ao aluno é requerida pouca } \\
\text { reflexão teórica. }\end{array}$ \\
\hline Acadêmica & $\begin{array}{l}\text { Há um esforço para propor uma situação- } \\
\text { problema, no entanto, a abordagem dos } \\
\text { conceitos envolvidos se dá de forma teórica e } \\
\text { tradicional através de aulas expositivas } \\
\text { centradas na figura do professor, e embora } \\
\text { haja alguma atividade experimental, esta } \\
\text { também é dirigida por ele. }\end{array}$ \\
\hline Projeto & $\begin{array}{l}\text { A situação-problema tenta conectar a teoria } \\
\text { com a prática e o estudante tende a ter um } \\
\text { papel protagonista; no entanto, as atividades } \\
\text { experimentais seguem passos determinados } \\
\text { pelo professor como em um roteiro. }\end{array}$ \\
\hline Investigadora & $\begin{array}{l}\text { Partem de uma situação-problema de } \\
\text { interesse dos alunos, propõem hipóteses, } \\
\text { constroem aparato experimental e tentam } \\
\text { chegar a conclusões de forma que, neste } \\
\text { processo, construam por si sós seu } \\
\text { conhecimento; se distingue de uma atividade } \\
\text { Indagadora por ter um pouco mais de } \\
\text { controle e mediação por parte do professor. }\end{array}$ \\
\hline
\end{tabular}




\begin{tabular}{|l|l|}
\hline \multirow{2}{*}{ Indagadora } & $\begin{array}{l}\text { Partindo da situação-problema de interesse } \\
\text { do o aluno, o mesmo tem total liberdade para } \\
\text { planejar suas atividades, desenvolver } \\
\text { hipóteses, construir aparato experimental a } \\
\text { fim de obter dados para construir modelos e } \\
\text { chegar a conclusões; há pouca ou nenhuma } \\
\text { interferência do professor, outorgando ao } \\
\text { aluno alto nível de autonomia. }\end{array}$ \\
\hline
\end{tabular}

\section{Resultados e discussões}

A turma foi dividida em equipes de cinco estudantes, o que forneceu uma amostra de oito sequências, cuja análise é apresentada a seguir.

\section{IV.1 Sequências didáticas dos Grupos 1 e 7: Acadêmica}

Há a proposição de uma atividade de caráter investigativo em ambas as sequências didáticas, mas a condução das atividades se concentra na figura do professor e os conceitos físicos são abordados de forma tradicional por meio de aulas expositivas.

Na SD do Grupo 1, é proposto o problema do Guia de Luz líquido para se trabalhar em uma turma de segundo ano do ensino médio. Este problema envolve conceitos como reflexão total da luz, refração da luz e princípio da fibra óptica. Na primeira aula é proposta uma aula expositiva, onde o professor deve abordar os conceitos físicos envolvidos no experimento do Guia de Luz Líquido, pois, segundo os autores desta sequência, "para que se compreenda um experimento, é importante saber os conceitos fisicos envolvidos na experiência". O caráter investigativo vem na segunda aula, onde os licenciandos propõem "uma aula inteiramente investigativa", na qual o professor deve realizar o experimento, incitando os alunos a levantarem hipóteses baseadas naquilo que foi exposto sobre os conceitos físicos, "sem ainda dar as respostas que os alunos devem obter por suas próprias observações”. É estimulada a interação entre os alunos, para que troquem ideias e conhecimentos. Ao final desta aula, o professor deve responder às hipóteses levantadas pelos alunos, explicando o fenômeno observado (a "curvatura" da luz junto com o jato de água). Nesta sequência, pode-se perceber a figura central do professor no processo de ensinoaprendizagem, apesar dos esforços para planejar uma aula menos tradicional.

Já na SD do Grupo 7, é proposto o problema Freios Magnéticos para se trabalhar de forma investigativa e não está especificado o público-alvo. Este problema envolve conceitos como lei de Faraday, lei de Lenz, entre outros. Na primeira aula, é proposto que o professor faça uma sondagem sobre os conhecimentos prévios dos alunos acerca do tema por meio de perguntas como: "já ouviram falar em magnetismo?”, “o que lhes vem à cabeça quando falamos sobre freios magnéticos?" etc. Após esta etapa inicial, o professor deve apresentar uma aula expositiva sobre os conceitos físicos envolvidos no problema, da mesma forma que 
o Grupo 1 propõe. Na segunda aula, também de forma semelhante ao Grupo 1, o Grupo 7 propõe uma aula investigativa, "onde os alunos, previamente cientes dos conceitos fisicos com os quais irão trabalhar, devem se dividir em grupos e cada grupo deve construir o experimento de freios magnéticos, para a seguir elaborarem hipóteses e as testarem, bem como discutirem entre si sobre as observações feitas a fim de que cada grupo possa chegar a uma conclusão que explique cientificamente o fenômeno observado". A construção do experimento, previamente elaborada pelo professor, deverá acontecer com a sua tutoria, embora ele não deva fornecer respostas aos alunos até o final deste momento. No final da aula, devem ser discutidas as hipóteses e conclusões (se houver) a que chegaram os alunos, mediadas pelo professor, que lhes explicará o experimento, correlacionando-o com os conceitos físicos pertinentes ao tema.

Nestas duas sequências didáticas pode-se perceber que os licenciandos, apesar de vivenciarem a abordagem investigativa durante todo um semestre com um considerado grau de liberdade para trabalho e investigação, têm dificuldades de planejar aulas em que essa liberdade esteja presente, deixando ainda a proposta de suas aulas muito concentradas na figura do professor, o que evidencia as dificuldades apresentadas por Campos e Scarpa (2018) e Lotter, Rushton e Singer (2016) no que se refere à resistência dos professores em formação inicial em romperem com o paradigma tradicional de ensino, ainda que haja a adesão, em parte, de uma abordagem alternativa. Também podemos destacar que, segundo Carvalho, Magno e Perez (2020) essa resistência pode estar associada com as inseguranças e angústias que as práticas pedagógicas não centradas na figura do professor podem trazer aos professores de modo geral por representarem uma mudança de postura que exige uma formação teórico-metodológica que, na maioria das vezes, não faz parte de seu caminho formativo.

\section{IV.2 Sequência didática do Grupo 3: Projeto}

O Grupo 3 planejou uma SD para uma turma de primeiro ano do ensino médio, propondo o problema Pesando o Tempo, que envolve conceitos físicos como força, gravitação (massa, leis de Newton), velocidade, aceleração e energia. O caráter investigativo já está presente na primeira aula da SD. É proposto que, ao apresentar o problema para a turma, um teste de sondagem seja feito para verificar os conhecimentos prévios dos alunos e estimular o interesse deles sobre o tema. Em seguida, a turma deve ser dividida em grupos e estes devem realizar o experimento proposto pelo professor para que sejam observados os fenômenos em questão e para que possam pensar em hipóteses para as relações de causa e efeito. Este momento é dirigido pelo professor, que deverá auxiliar os alunos e estimulá-los com perguntas. Os grupos formados devem continuar investigando o problema para apresentarem uma possível explicação/solução na terceira aula. Na segunda aula, é proposto que o professor "dê uma aula tradicional (usando quadro ou slides) sobre os conceitos fisicos envolvido no problema, de forma a orientar o entendimento dos alunos em suas 
pesquisas e também para esclarecer dúvidas sobre conceitos". Na terceira aula, como dito anteriormente, "os grupos devem apresentar a(s) conclusão(ões) a que chegaram em forma de seminários curtos”, promovendo a argumentação científica dos resultados. A ideia de realizar um experimento antes da explicação dos conceitos físicos envolvidos nele é um indício de que o Grupo 3 demonstrou entendimento razoável sobre os aspectos da abordagem investigativa, ainda que apresentem recursos mais tradicionais como realização de aulas expositivas centradas na explicação do professor; a liberdade conferida aos alunos também é um indicativo disso. No entanto, este resultado também corrobora com o proposto por Lima, Belíssimo e Nardi (2020) quando evidenciamos que os professores em formação, apesar de planejarem aulas com abordagem investigativa, ainda acabam por amparar a sua prática em sala de aula no paradigma tradicional de ensino, mesmo que entendam os benefícios da utilização de abordagens alternativas (CAMPOS; SCARPA, 2018), suas concepções acerca dos estudantes, da Ciência e dos processos de ensino-aprendizagem podem ser limitantes na hora de se apropriar de tais abordagens (CARDOSO; SCARPA, 2018).

\section{IV.3 Sequência didática do Grupo 6: Investigadora.}

O Grupo 6 foi o único a planejar uma SD com considerado grau de abordagem investigativa. Pensada para uma turma de primeiro ano do ensino médio, ela propõe uma sequência de aulas de caráter investigativo para ensinar sobre o movimento de queda livre. Na primeira aula, um teste de sondagem é proposto para verificar os conhecimentos prévios dos alunos sobre o tema. Perguntas como: "corpos mais pesados tendem a cair mais rápido?" são sugeridas para estimular o interesse dos alunos. Após as discussões iniciais, a turma deve ser dividida em grupos e um problema de investigação sobre o tema deve ser proposto pelo professor. Cada grupo deve, então, "investigar o problema, procurar fontes como livros e internet, onde possam aprender e discutir entre si sobre os conceitos físicos relacionados com o problema, levantar suas hipóteses, construir um aparato experimental que lhes permita analisar as variáveis envolvidas e coletar dados para que ao final sejam apresentadas soluções" baseadas em argumentos científicos. Por isso, na segunda aula, propõe-se um momento em que o professor esteja disponível para auxiliar os grupos sobre algum aspecto técnico do experimento ou para tirar dúvidas sobre conceitos pertinentes ao problema. Assim, o professor deve atuar como um mediador, estando solícito para cada grupo, incentivando e facilitando o engajamento e o aprendizado dos alunos. Na terceira aula, então, sugere-se que cada grupo realize sua argumentação, mesmo que não tenham chegado a conclusões, evidenciando quais foram suas dificuldades. Embora este tenha sido o único grupo a propor uma SD com relevante grau de liberdade de investigação, esse resultado corrobora o proposto por Tabosa et al. (2018) ao evidenciar que, a vivência da abordagem investigativa na formação inicial estimula o futuro professor à reestruturação da prática docente ao lhe inspirar a planejar e construir aulas mais dinâmicas, que promovam o engajamento e o protagonismo do estudante. Não se tem a pretensão de dizer que o sucesso 
do grupo nesta tarefa é o suficiente para determinar que serão professores com uma prática e uma visão de ensino diferenciadas, tampouco que serão adeptos da abordagem investigativa, pois é preciso considerar que o processo de formação é contínuo, mas sem dúvida pode-se considerar que seja um resultado promissor quando se leva em consideração as várias dificuldades mencionadas para formar professores que consigam pensar uma prática fora do padrão tradicional.

\section{IV.4 Sequências didáticas dos Grupos 2, 4, 5 e 8: Não se aplica}

As SD destes grupos não puderam ser categorizadas de acordo com o instrumento de análise utilizado por não apresentarem o aspecto mais básico da abordagem investigativa que é a proposição de uma situação-problema como ponto de partida. Estas SD estão mais caracterizadas como planos de aulas em que se propõe o ensino de tópicos da Física por meio de aulas expositivas que giram em torno das explicações do professor.

$\mathrm{Na}$ SD apresentada pelo Grupo 2 foi proposto o problema Canhão Eletromagnético, para ser trabalhado em uma turma de terceiro ano do ensino médio. Na primeira aula deve ser aplicado um teste de sondagem para verificar os conhecimentos prévios dos alunos sobre os conceitos envolvidos no tema. Essa discussão deve ser guiada pelo professor, que tenta induzir os alunos a fazerem correlações entre os conceitos e situações cotidianas. No entanto, nas duas aulas seguintes é proposto que o professor "dê aulas expositivas sobre os conceitos envolvidos no tema, utilizando quadro elou slides como recurso". Na quarta aula, a turma deve ser dividida em grupos para a "realização de uma competição de perguntas $e$ respostas". O problema do Canhão Eletromagnético só e citado na quinta aula, como um recurso demonstrativo dos conceitos físicos que o professor abordou.

Já o Grupo 8 não propõe nenhum problema de investigação como ponto de partida, e o tópico da aula é o estudo do vácuo. No início da primeira aula é proposto um teste de sondagem e ao final os alunos são instruídos a fazer uma breve pesquisa em casa utilizando fontes como livros e internet sobre os conceitos físicos envolvidos no tema. O grupo chega a propor alguma experimentação na segunda aula, mas assim como o Grupo 2, apenas como recurso demonstrativo das aulas expositivas. Na terceira aula é proposto fazer apenas um teste avaliativo em forma de questionário.

A SD do Grupo 5 propôs o ensino de tópicos de magnetismo, também para uma turma de terceiro ano do ensino médio. Não é apresentado um problema de investigação como ponto de partida, e as aulas são realizadas de forma tradicional, onde "o professor pode expor os conceitos partindo dos conhecimentos prévios da turma, usando slides e experimentos", com pouca participação ativa dos alunos.

Já na SD do grupo 4, não houve qualquer proposição de um problema de investigação nem mesmo experimentação em aula. Apenas é proposto o tema velocidade e as aulas são expositivas. 
Vemos assim que metade das sequências didáticas produzidas não puderam ser categorizadas de acordo com a rubrica adotada, pois não apresentaram os aspectos básicos de um ensino baseado em investigação. Este resultado nos suscita algumas importantes reflexões acerca das dificuldades apresentadas pelos licenciandos. A primeira que podemos destacar é que, apesar de vivenciarem a abordagem investigativa na prática, eles não conseguiram compreender os aspectos teóricos e metodológicos básicos do ensino por investigação. Houve dificuldades explícitas em planejar uma sequência didática com uma abordagem ativa de ensino e esse resultado não destoa da literatura da pesquisa da área. Seung, Park e Jung (2014) chamam a atenção sobre as dificuldades que os professores em formação inicial apresentam em deixar de concentrar suas ações em si mesmos e focar no aluno, verdadeiro sujeito protagonista dos processos de ensino-aprendizagem. Isso fica evidente quando metade das SD têm no centro das aulas a figura do professor.

A outra dificuldade que podemos pontuar neste resultado é a própria resistência dos licenciandos de mudar a forma de ensinar com a qual já estão habituados (CARVALHO; MAGNO; PEREZ, 2020). Quando estamos na condição de alunos, nossas concepções sobre o ensino são construídas a partir dos modelos de ensino que vivenciamos. Dessa forma, os professores, que um dia foram alunos, passam a reproduzir em sua prática docente a maneira com que foram ensinados. Romper esse paradigma é um processo que precisa ser intermediado por uma formação que deve começar desde o primeiro semestre dos cursos de licenciatura e continuar para além deles.

Também podemos destacar a incapacidade dos licenciandos de propor um problema de investigação. Habituados a responder problemas estruturados e fechados com variáveis bem definidas, em condições ideais e se valendo de equações matemáticas já estabelecidas, se constitui um enorme desafio pensar questões fora desse padrão. Nesse contexto, Giordan, Guimarães e Massi (2011) acreditam ser importante salientar as dificuldades que a distância existente entre o que se aprende a universidade e sua efetiva implementação agregam à prática docente. Na Fig. 1 podemos observar os resultados encontrados:

Resultados similares a estes podem ser encontrados nos estudos de Schwarz e Gwekwerere (2007) e Toma, Greca e Villagrá (2017). Como exemplo, citamos o estudo de Greca, Villagrá e Ojeda (2017) com estudantes da graduação em Magistério da Educação Primária da Universidade de Burgos na Espanha. Utilizando a rubrica desenvolvida por Schwarz e Gwekwerere (2007), analisaram as sequências didáticas produzidas por uma turma de estudantes ao final de um ciclo de três disciplinas de Ciências de segundo, terceiro e quarto ano do curso. A abordagem investigativa foi utilizada durante as disciplinas. Os resultados deste estudo mostraram que, mesmo tendo considerável contato com a abordagem durante as três disciplinas, metade das sequências didáticas produzidas foram categorizadas entre Prática Coerente e Prática Incoerente e apenas 22\% entre Investigadora e Indagadora. 


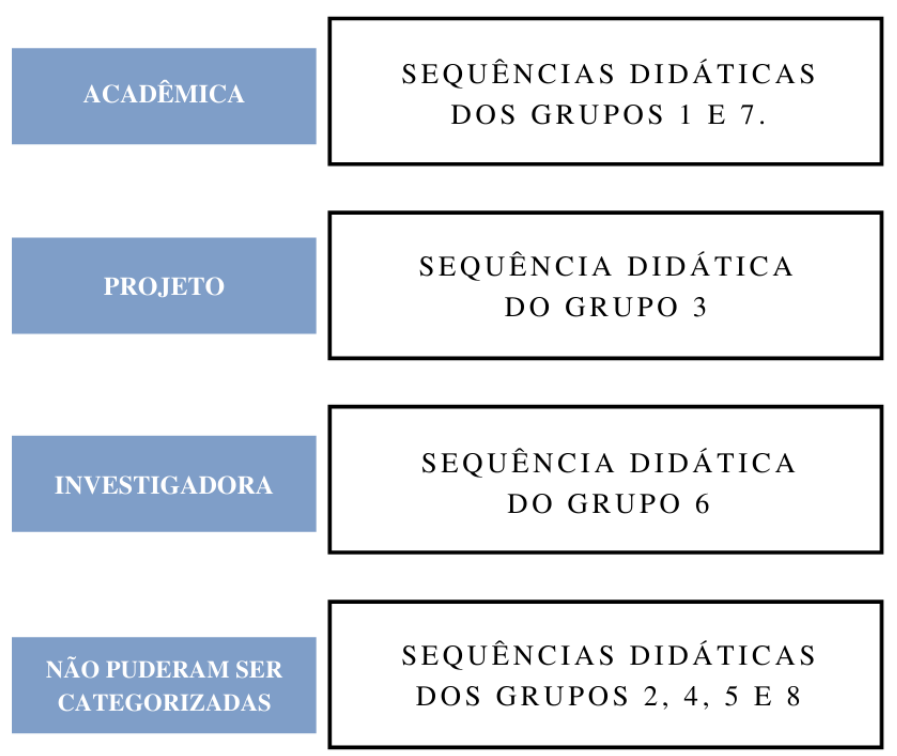

Fig. 1 - Síntese da categorização das sequências didáticas produzidas pelos grupos da turma.

\section{Considerações finais}

Considerando que é necessário repensar o ensino de Física, buscou-se neste trabalho compreender como a formação inicial de professores pode ser um fator determinante para a promoção de um ensino de qualidade. Neste sentido, consideramos ser de grande relevância o papel das abordagens didáticas alternativas que coloquem o aluno no centro dos processos de ensino-aprendizagem. Destaca-se neste estudo o ensino por investigação como uma abordagem ativa capaz de oportunizar situações de aprendizagem em que os estudantes possam desenvolver as várias dimensões da competência científica. Partindo do pressuposto de que é necessário formar professores capacitados para se apropriarem de abordagens didáticas alternativas para enfrentar e dirimir as dificuldades nas salas de aula de Física, buscou-se compreender como a utilização de abordagem investigativa em disciplinas de conteúdo específico da formação inicial de professores pode estimular e capacitar estes professores a incorporar essa abordagem na sua prática docente.

Assim, foram analisadas as sequências didáticas produzidas por uma turma composta de oito grupos de estudantes que cursaram a disciplina Física Elementar Conceitual do curso de licenciatura em Física da UFPA. A abordagem didática usada para conduzir esta disciplina foi o ensino por investigação. Como instrumento metodológico de análise foi utilizada uma rubrica que apresenta a categorização de seis tipos de sequências didáticas conforme seu grau de investigação.

A análise das oito sequências didáticas apresentou o seguinte resultado: duas foram categorizadas como Acadêmicas, indicando dificuldades de elaborar aulas menos verticais e 
mais centradas no aluno, uma como Projeto, onde se propõe aulas com maior liberdade dos alunos dentro das atividades de investigação e uma como Investigadora, indicando relevante compreensão dos aspectos teóricos e metodológicos básicos da abordagem investigativa. Já as quatro sequências restantes não puderam ser categorizadas, pois não apresentaram a proposta de um problema de investigação que servisse como ponto de partida para o desenvolvimento das aulas.

Os resultados apresentados evidenciam as muitas dificuldades envolvidas no processo de reestruturação da prática pedagógica. Entendemos que uma renovação epistemológica e didático-metodológica se faz necessária para que os professores estejam mais conscientes de seu papel na busca por uma educação que promova a alfabetização científica e a formação de cidadãos críticos, preparados para os atuais desafios da sociedade. Essa renovação é intermediada por um processo formativo contínuo que precisa começar desde os primeiros semestres dos cursos de licenciatura e ir para além deles. Assim, pode-se concluir que a utilização de abordagens didáticas alternativas, como o ensino por investigação no âmbito da formação inicial de professores, se apresenta como um valioso recurso formativo que, trabalhado em suas várias dimensões, pode contribuir na construção de sujeitos capazes de repensar a própria prática e de redefinir suas concepções sobre Ciência, sobre os estudantes e sobre o ensino.

\section{Agradecimento}

À Faculdade de Física da Universidade Federal do Pará (UFPA). À Pró-Reitoria de Pesquisa e Pós-Graduação (PROPESP/UFPA). Ao Grupo de Pesquisa em Ensino de Física da UFPA (GPEF/UFPA).

\section{Referências bibliográficas}

ADADA, F. Estudo sobre a percepção do discente sobre as metodologias ativas na educação superior. 2017. 142f. Dissertação (Mestrado em Educação) - Centro de Educação, Comunicação e Artes, UNIOESTE, Cascavel.

BAPTISTA, G. C. S. A importância da reflexão sobre a prática de ensino para a formação docente inicial em Ciências Biológicas. Ensaio Pesquisa em Educação em Ciências, Belo Horizonte, v. 5, n. 2, p. 4-12, dez. 2003.

BAZZO, W. A. et al. O que é ciência? In: BAZZO et al. (Orgs.). Introdução aos estudos CTS (ciência, tecnologia e sociedade). Madri: OEI, 2003. Cap. 1. p. 35-80.

BRASIL. Ministério da Educação. Parâmetros Curriculares Nacionais. Brasília, 1997. 
BRASIL. Ministério da Educação. Plano Nacional de Educação. Brasília, 2014.

BRASIL. Ministério da Educação. Base Nacional Comum Curricular. Brasília, 2018.

CACHAPUZ, A. et al. (Orgs.). A necessária renovação do ensino das ciências. São Paulo: Cortez, 2005.

CAMPOS, N. F.; SCARPA, D. L. Que desafios e Possibilidades Expressam os Licenciandos que começam a aprender sobre ensino de Ciências por Investigação? Tensões entre visões de Ensino centradas no professor e no estudante. Revista Brasileira de Pesquisa em Educação em Ciências, v. 18, n. 2, p. 727-759, ago. 2018.

CANÃL, P. Saber ciencias no equivale a tener competencia profesional para enseñar ciências. In: PEDRINACI, E. (Coord.). El desarrollo de la competencia científica. Barcelona: Graó, 2012. p. 217-239.

CARDOSO, M. J. C.; SCARPA, D. L. Diagnóstico de elementos do Ensino de Ciências por Investigação: uma ferramenta de análise de propostas de ensino investigativo. Revista Brasileira de Pesquisa em Educação em Ciências, v. 18, n. 3, p. 1025-1059, set. 2018.

CARVALHO, A. M. P.; GIL-PÉREZ, D. Formação de professores de Ciências: tendências e inovações. São Paulo: Cortez, 2011.

CARVALHO, A. M. P.; SASSERON, L. H. Ensino e aprendizagem de Física no Ensino Médio e a formação de professores. Estudos Avançados, São Paulo, v. 32, n. 94, p. 43-55, 2018. Disponível em: <https://www.revistas.usp.br/eav/article/view/152655>. Acesso em: 7 mai. 2020.

CARVALHO, I. S.; MAGNO, F. N. B.; PEREZ, S. Reação de estudantes de bacharelado no processo de ensino-aprendizagem de conceitos físicos com abordagem investigativa: um relato de experiência na Universidade Federal do Pará. In: ENCONTRO NACIONAL DE ENSINO DE CIÊNCIAS POR INVESTIGAÇÃO (ENECI), 2, 2020, online. Anais...

CARVALHO, J. F. M.; CARVALHO, I. S.; PEREZ, S. Atividades investigativas no ambiente universitário: um relato de participação discente no plano piloto aplicado no primeiro semestre de graduação em Física na UFPA. In: ENCONTRO NACIONAL DE ENSINO DE CIÊNCIAS POR INVESTIGAÇÃO (ENECI), 2, 2020, online. Anais... 
COELHO, G. R.; AMBRÓZIO, R. M. O ensino por investigação na formação inicial de professores de Física: uma experiência na Residência Pedagógica de uma universidade pública federal. Caderno Brasileiro de Ensino de Física, v. 36, n. 2, p. 490-513, ago. 2019.

DARUB, A. K. G. S; SILVA, O. R. Formação de professores e metodologias ativas. In: CONGRESSO INTERNACIONAL DE EDUCAÇÃO E TECNOLOGIAS (CIET), 5, 2020, online. Anais...

DOMINGUES, G. H. C.; NASCIMENTO, W. J.; VALÉRIO, M. Iniciação à docência em Física inspirada no ensino por investigação. Revista Extensão em Foco, v. 19, p. 72-85, 2019. Disponível em: <https://revistas.ufpr.br/extensao/article/view/63871>. Acesso em: 7 mai. 2020.

DUARTE, V. G. Metodologias ativas e ensino de Ciências na Educação Superior: um estudo a partir da percepção do aluno. 2018. 114f. Dissertação (Mestrado em Educação em Ciências) - Universidade Federal de Itajubá, Itajubá.

GIORDAN, M.; GUIMARÃES, Y.; MASSI, L. Uma análise das abordagens investigativas de trabalhos sobre sequências didáticas: tendências no ensino de Ciências. In: ENCONTRO NACIONAL DE PESQUISA EM EDUCAÇÃO EM CIÊNCIAS (ENPEC), VIII, 2011, Campinas. Anais... Rio de Janeiro: ABRA, 2011.

GOLOMBEK, D. A. Aprender e ensinar Ciências: do laboratório à sala de aula (e viceversa). 2. ed. São Paulo: Sangari do Brasil, 2009.

GRECA, I. M.; VILlAGRÁ, J. A. M.; OJEDA, M. D. La formación en Ciencias de los estudiantes del grado en maestro de Educación Primaria. Revista Electrónica de Enseñanza de las Ciencias, v. 16, n. 2, p. 231-256, 2017. Disponível em:

$<$ http://reec.uvigo.es/REEC/spanish/REEC_older_es.htm>. Acesso em: 7 mai. 2020.

INTERNATIONAL YOUNG PHYSICIST TOURNMENT. Problemas. Disponível em: $<$ http://www.iypt.com.br/problemas $>$. Acesso em: 27 jan. 2020.

KRÄMER, P; NESSLER, S. H.; SCHLÜTER, K. Teacher student's dilemmas when teaching science through inquiry. Research in Science \& Techonogical Education, v. 33, n. 3, p. 1$19,2015$. 
LEDERMAN, J. et al. An international collaborative investigation of beginning seventh grade students' understandings of scientific inquiry: establishing a baseline. Jornal of Research in Science Teaching, v. 53, n. 4, p. 486-515, 2019.

LIMA, A. C. A.; BELÍSSIMO, J. R.; NARDI, R. Os sentidos atribuídos por licenciandos em Física sobre o ensino por investigação. In: ENCONTRO DE PESQUISA EM ENSINO DE FÍSICA (EPEF), XVIII, 2020, online. Anais...

LORENZETTI, L.; DELIZOICOV, D. Alfabetização científica no contexto das séries iniciais. Ensaio Pesquisa em Educação em Ciências, Belo Horizonte, v. 3, n. 1, p. 45-61, 2001.

LOTTER, C.; RUSHTON, G. T.; SINGER, J. Teacher enactment patterns: how can we help move all teachers to reform-based inquiry practice through professional development? Journal of Science Teacher Education, v. 248, p. 1263-1291, 2016.

MONTEIRO, P. V. R.; SILVA, G. L. R.; ROSSLER, J. H. A apropriação de conceitos científicos no contexto escolar e as pedagogias do aprender a aprender. Psicologia Escolar e Educacional, São Paulo, v. 20, n. 3, p. 551-560, 2016.

MOREIRA, M. A. Uma análise crítica do ensino de Física. Estudos Avançados, São Paulo, v. 32, n. 94, p. 73-80, set. 2018. Disponível em:

$<$ https://www.scielo.br/j/ea/a/3JTLwqQNsfWPqr6hjzyLQzs/?lang=pt>. Acesso em: 7 mai. 2020 .

MUNFORD, D.; LIMA, M. E. Ensinar Ciências por investigação: em quê estamos de acordo? Ensaio Pesquisa em Educação em Ciências, Belo Horizonte, v. 9, n. 1, p. 89-111, 2007.

NATIONAL RESEARCH COUNCIL. National science education standards. Washington: National Academy Press, 1996.

NATIONAL RESEARCH COUNCIL. Inquiry and the national science education standards: a guide for teaching and learning. Washington: National Academies Press, 2000.

NATIONAL RESEARCH COUNCIL. A framework for K-12 science education: Practices, crosscutting concepts, and core ideas. Washington: National Academies Press, 2012.

NGSS LEAD STATES. Next generation science standards: For states, by states. Washington: National Academies Press, 2013. 
PARANHOS, M. C. R. et al. Metodologias ativas no ensino de física: uma análise comparativa. Revista Ensino e Pesquisa, v. 14, n. 36, p. 124-131, 2017.

PEREZ, S. et al. O pêndulo defasado: um exemplo de sistema caótico para estudantes do ciclo inicial do curso de graduação em Física. Revista do Professor de Física, v. 2, n. 3, 2018. Disponível em: <https://periodicos.unb.br/index.php/rpf/article/view/19049>. Acesso em: 10 mai. de 2020.

PEREZ, S.; VILLAGRÁ, J. A. M. La competencia científica en las actividades de aprendizaje incluidas en los libros de texto de Ciencias de la Naturaleza. Revista Eureka sobre Enseñanza y Divulgación de las Ciencias, Andaluzia, v. 17, n. 2, p. 2101-3 a 2101-18, 2020.

PROGRAMME FOR INTERNATIONAL STUDENT ASSESSMENT. Marco de la evaluación: conocimientos y habilidades en Ciencias, Matemáticas y Lectura. Madrid: Santillana Educación, 2006.

SCHWARZ, C. V.; GWEKWERERE, Y. N. Using a guide inquiry and modeling instructional framework (EIMA) to support preservice K-8 science teaching. Science Education, v. 91, n. 1, p. 158-186, 2007.

SEUNG, E. P.; PARK, S. JUNG, J. Exploring preservice elementary teacher's understanding of the essential features of inquiry-based science teaching using evidence-based reflection. Research in Science Education, v. 44, n. 4, p. 507-529, 2014.

TABOSA, C. E. S. et al. Atividades investigativas e o desenvolvimento de habilidades e competências: um relato de experiência do curso de física da Universidade Federal do Pará. Revista Brasileira de Ensino de Física, v. 40, n. 4, 2018.

TOMA, R. B.; GRECA, I. M.; VILLAGRÁ, J. A. M. Dificultades de maestros en formación inicial para diseñar unidades didácticas usando la metodología de indagación. Revista Eureka sobre Enseñanza y Divulgación de las Ciencias, Andaluzia, v. 14, n. 2, p. 442-457, 2017.

VAN UUM, M. S. J; VERHOEFF, R. P.; PEETERS, M. Inquiry-based science education: towards a pedagogical framework for primary school teachers. International Journal of Science Education, v. 38, n. 3, p. 450-469, 2016.

ZABALA, A. A prática educativa: como ensinar. Porto Alegre: Artmed, 1998. 
ZÔMPERO, A. F.; GONÇALVES, C. E. S.; LABURÚ, C. E. Atividades de investigação na disciplina de Ciências e desenvolvimento de habilidades cognitivas relacionadas a funções executivas. Ciência \& Educação, Bauru, v. 23, n. 2, p. 419-436, 2017.

ZÔMPERO, A. F.; LABURÚ, C. E. Atividades investigativas no ensino de Ciências: aspectos históricos e diferentes abordagens. Ensaio Pesquisa em Educação em Ciências, Belo Horizonte, v. 13, n. 3, p. 67-80, 2011.

ZÔMPERO, A. F.; LABURÚ, C. E. Atividades investigativas para as aulas de Ciências: um diálogo com a Teoria da Aprendizagem Significativa. Curitiba: Apriss, 2016.

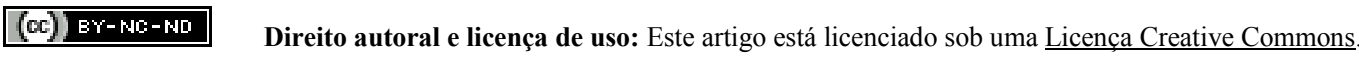

